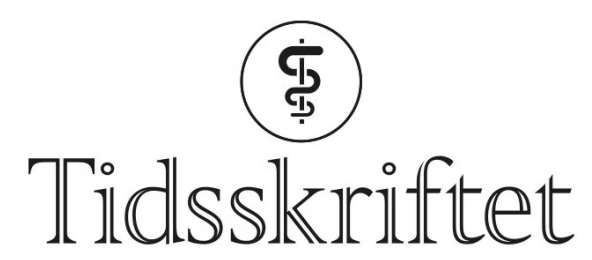

DEN NORSKE LEGEFORENING

\title{
Stramt tungebånd hos nyfødte
}

KRONIKK

\section{ANE CHARLOTTE HAUG}

Ane Charlotte Haug er lege i spesialisering del 1 ved Universitetssykehuset Nord-Norge, Harstad. Forfatteren har fylt ut ICMJE-skjemaet og oppgir ingen interessekonflikter.

\section{TROND MARKESTAD}

Leder, Rådet for legeetikk

\section{ERLING TJORA}

Erling Tjora er overlege ved Barne- og ungdomsklinikken, Haukeland universitetssjukehus og postdoktor ved Klinisk institutt 2, Universitetet i Bergen.

Forfatteren har fylt ut ICMJE-skjemaet og oppgir ingen interessekonflikter.

\section{DAG MOSTER}

dag.moster@uib.no

Dag Moster er overlege Barne- og ungdomsklinikken, Haukeland universitetssjukehus og professor ved Institutt for global helse og samfunnsmedisin, Universitetet i Bergen.

Forfatteren har fylt ut ICMJE-skjemaet og oppgir ingen interessekonflikter.

\section{I løpet av de siste årene har en økende andel nyfødte fått klippet tungebåndet på grunn av ammeproblemer. Evidensgrunnlaget for nytten av behandling er imidlertid svakt. Vi er bekymret for at stadig flere nyfødte blir unødig utsatt for dette inngrepet.}

Stramt tungebånd (ankyloglossi) hos nyfødte har fått økende oppmerksomhet nasjonalt og internasjonalt fordi flere mener at det er en viktig årsak til ammeproblemer (1-3). Imidlertid er både diagnosen og den kliniske betydningen omdiskutert (4-9.). Dette illustreres ved at rapportert prevalens varierer fra under $1 \%$ til $12 \%$ hos nyfødte og ved at et $\emptyset$ kende antall nyfødte har fått diagnosen de siste årene (5-10). Ifølge Norsk pasientregister fikk 2,8 \% av nyfødte barn i Norge diagnosen i 2019, og 2,2 \% fikk utført operasjon på tungebåndet i løpet av de første fire leveukene (figur 1). Dette året ble diagnosen stilt 7 ganger oftere og inngrepet foretatt 13 ganger hyppigere enn i 2008 (figur 1). Tilsvarende utvikling skjer også i andre land $(\underline{6}$, .7.). Det er imidlertid liten enighet om grunnlaget for diagnosen, hvilke symptomer tilstanden gir og indikasjon for behandling $(3-5),(5, \underline{11}, \underline{12})$. 
Etter gjennomgang av relevant litteratur og ut fra vår kliniske erfaring mener vi det er grunnlag for en mer forsiktig anvendelse av kirurgisk behandling enn den tendensen vi opplever i dag.

Q38.1 Ankyloglossi —EJC20 Operasjon på tungebånd

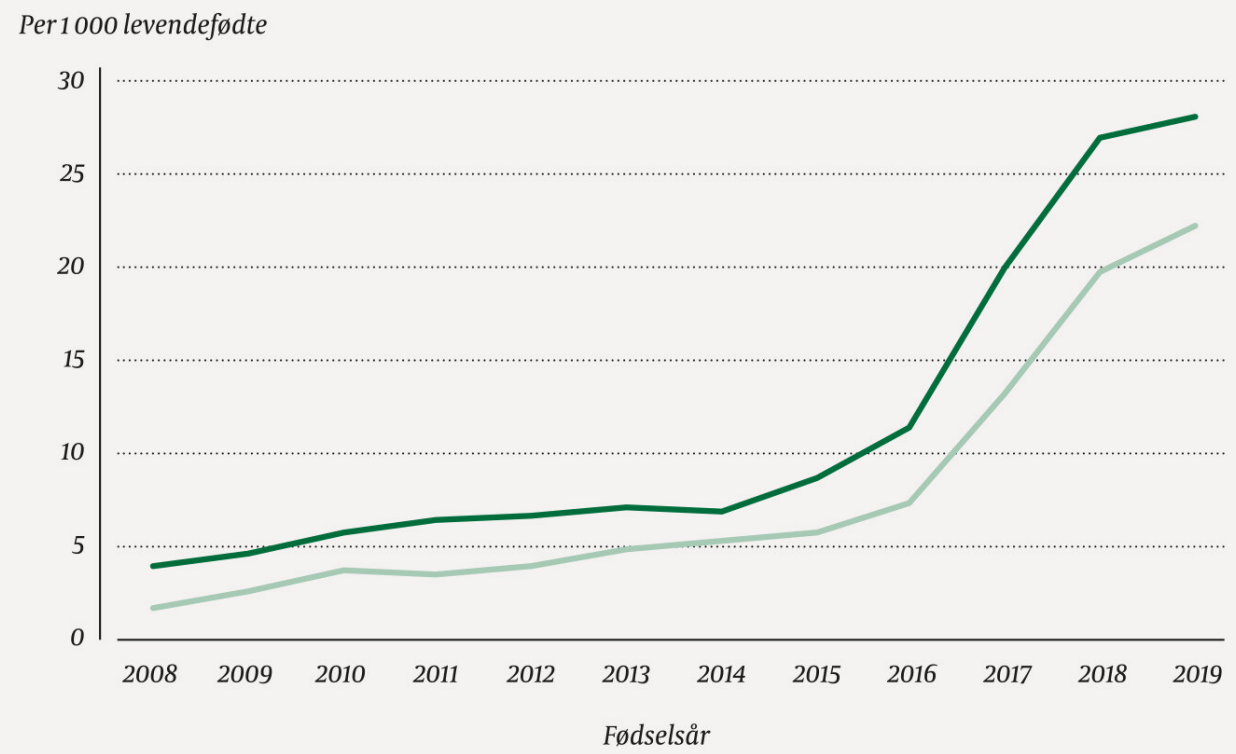

Figur 1 Andel barn født i Norge i perioden 2008-19 som fikk diagnosen ankyloglossi i løpet av de første fire leveukene og som fikk utført operativt inngrep på tungebåndet. Tall hentet fra Norsk pasientregister.

\section{Tungebåndet}

Tungebåndet (frenulum linguae) er en foldet mukøs membran, som bidrar til å stabilisere basis av tungen ved å binde tungen til munngulvet $(5, \underline{13}, 14$.). Ankyloglossi oppfattes vanligvis som en anatomisk variant der tungebåndet er så kort, hypertrofisk eller stramt at tungen ikke får tilstrekkelig fri bevegelighet $(\underline{2}, 5)$. Tungebåndet kan enten være festet for nær tungespissen og for langt framme mot alveolarranden i munngulvet, eller lenger bak på tungen og i munngulvet, men være så kort at det hemmer bevegeligheten. Når tungen løftes, vil tungespissen kunne få en hjerteform (2). Noen klassifiserer ankyloglossi som en medfødt misdannelse av genioglossusmusklene (15). Tilstanden har fått en egen ICD-10kode, Q38.1 Ankyloglossi (무).

Begrepet bakre tungebånd er omdiskutert $(4, \underline{17}, \underline{18})$. Noen hevder at begrepet beskriver de funksjonelle symptomene ved stramt tungebånd, uten at det nødvendigvis kreves et synlig stramt eller kort tungebånd $(3, \underline{18})$. Ifølge Barnelegeforeningens veileder i pediatri er bakre tungebånd kun en noe tykkere submukosa i bakre del av tungebåndet, og det understrekes at det finnes bare ett tungebånd (19.). Begrepet kan også være misvisende fordi årsaken til nedsatt bevegelighet i tungen kan være sammensatt, uten å være knyttet til tungebåndet (17.).

Det er ingen kjent embryologisk årsak til ankyloglossi. Det er foreslått at kort slimhinne og økt fibromuskulært vev i midtlinjen kan skyldes mangelfull utvikling av fremre delen av tungen kombinert med ufullstendig tilbakedannelse (apoptose) i de midtre tungeanleggene samt $ø \mathrm{kt}$ sammenvoksing i de laterale anleggene $(\underline{8}, \underline{20})$.

Tungens funksjon er av betydning for at barnet skal oppnå et godt sugetak på morens bryst (21). Ultralydundersøkelser utført på spedbarn som dier, kan tyde på at god tungemobilitet og evne til å skape vakuum er nødvendig for effektiv amming (22-25). Et for stramt tungebånd kan tenkes å føre til vansker ved at bevegeligheten av tungen begrenses $(5,13)$. 
Symptomer på ankyloglossi vektlegges ulikt avhengig av barnets alder $(\underline{2}, 3)$. I nyfødtperioden står ammeproblemer sentralt, samtidig som de fleste barna med stramt tungebånd ser ut til å kunne die normalt (3). I flere studier har man undersøkt sammenhengen mellom stramt tungebånd og ammeproblematikk, og i hovedsak beskrives vansker med å etablere et godt sugetak, smerter under amming og såre brystvorter $(5,9, \underline{26})$. Det kan videre føre til svekket melkeutdrivning, nedsatt melkeproduksjon, tette melkeganger og mastitt $(\underline{8}, \underline{10}, \underline{21}, \underline{27}$.). Stramt tungebånd alene ser ikke ut å kunne forklare ammeproblemene, men må ses i sammenheng med andre

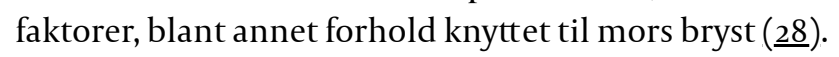

Dievansker kan vise seg på ulike måter. Dårlig sugetak gjør at barnet kan miste taket under ammingen. Det kan vise seg ved at barnet lager klikkelyder når vakuumet forsvinner, lang dietid, irritabilitet og dårlig vektoppgang $(\underline{8}, \underline{10}, \underline{21})$. Det er omstridt i hvor stor grad ankyloglossi er medvirkende årsak til disse symptomene, men de inngår i flere diagnosekriterier for ankyloglossi appendiks 1). Stramt tungebånd ser ikke ut til å påvirke evnen til å suge fra flaske, sannsynligvis fordi barnet bruker annen sugeteknikk fra flaske enn fra bryst ((3).

\section{Forekomst og kriterier}

Den store variasjonen i rapportert forekomst av ankyloglossi reflekterer de ulike kriteriene som legges til grunn. Det er ingen enighet om verken definisjon eller graderingssystem. Tolkingen kompliseres også av at ammeproblemer ofte kan ha andre årsaker. I en studie ble tilstanden diagnostisert hos 3,2 \% av brysternærte nyfødte i løpet av barnets to første levedøgn (9.). Hos nyfødte henvist for ammeproblemer viser studier varierende forekomst av stramt tungebånd, fra 12,8 \% til 56\% (9,29,3으). Den store økningen i forekomsten i Norge kan skyldes økt oppmerksomhet, tidligere underrapportering eller en tendens til overdiagnostisering i senere år (figur 1 ).

Forekomsten ut over tidlig spedbarnsalder er lite undersøkt og dermed usikker (31-33), men den ser ut til å avta. Det kan skyldes redusert klinisk betydning når barna ikke lenger dier, eller at vekst av munnen og tungen endrer det anatomiske og funksjonelle bildet. Det er ikke vist sikre sammenhenger mellom stramt tungebånd og andre symptomer (for eksempel uttalevansker) enn problemer knyttet til amming (34,35).

\section{«For spedbarn er det gjort flere fors $ø k$ på å lage klassifikasjons- og vurderingskriterier, men til nå er det ingen allment aksepterte kriterier for å stille diagnosen eller anbefale behandling»}

For spedbarn er det gjort flere forsøk på å lage klassifikasjons- og vurderingskriterier, men til nå er det ingen allment aksepterte kriterier for å stille diagnosen eller anbefale behandling. Det anvendes derfor forskjellig beslutningsgrunnlag $(3, \underline{4}, \underline{8}, \underline{10})$. Oversikt over ulike vurderingskriterier og behandlingsindikasjoner er gitt i appendiks 1 .

\section{Behandlingsalternativer}

Ammeveiledning bør forsøkes først, og kan redusere behovet for kirurgisk behandling (3흐, 37.). Den vanligste kirurgiske behandlingen hos nyfødte er frenulotomi, ofte kalt klipping. Det anvendes saks eller kniv, med eller uten lokalbedøvelse. Frenulektomi (eksisjon av 
frenulum), frenuloplastikk og laserbehandling anvendes også ( $\underline{8}, \underline{22})$. Det foreligger lite dokumentasjon på effekten av ikke-invasive behandlingsformer, som for eksempel fysioterapi, tungetøying eller kraniosakral terapi $(\underline{8}, 3 \underline{8})$.

De siste årene har det blitt publisert to systematiske oversikter og en Cochrane-oversikt rundt effekten av frenulotomi ved ammeproblemer $(5,38,39$.). De er basert på randomiserte kliniske studier og systematiske litteraturs $ø \mathrm{k}$ som inkluderer randomiserte fors $\emptyset \mathrm{k}$ og kohortstudier. I alle disse oversiktene er det pekt på at samtlige inkluderte studier var av lav kvalitet og hadde metodiske svakheter, blant annet små studiepopulasjoner og manglende randomisering. En høyere andel av mødrene til barna som var behandlet, rapporterte mindre smerte under ammingen i en kort periode. Det er lite kunnskap om langtidseffekter.

Frenulotomi regnes som en hovedsakelig trygg prosedyre, men blødning, infeksjon, skade på tunge og utførselsgangene til glandula submandibularis samt tilbakefall av symptomer forekommer (3,4으). Det har også vært bekymring knyttet til smerten som påføres spedbarnet under og etter inngrepet (41). Oversiktene poengterer at det mangler forskning på hva som er et ideelt tidspunkt for frenulotomi samt på god smertelindring og hvilken effekt frenulotomi har på melkeproduksjon og ammevarighet (5).

\section{Retningslinjer}

Oversikt over veiledere og retningslinjer fra ulike land og organisasjoner er gitt i appendiks 2. Disse framhever ofte selv at anbefalingene er svake fordi de bygger på studier med lav evidenskvalitet. Flertallet av veilederne anbefaler ammeveiledning som første behandlingstrinn og åpner opp for at frenulotomi kan utføres dersom ammeveiledning ikke er tilstrekkelig og de diagnostiske kriteriene er oppfylt. Veilederne er lite samstemte om hvilke vurderingskriterier som bør brukes, og det etterspørres diagnostiske kriterier for å kunne gi tydelige retningslinjer $(5, \underline{8})$.

\section{«Der det er lite evidens for at den radikale behandlingsmåten er bedre enn den konservative, mener vi det klokeste valget er å velge det alternativet som gir minst skade og smerte for barnet»}

Nasjonalt kompetansesenter for amming ga i 2021 ut en veileder for diagnostikk og behandling av stramt tungebånd hos spedbarn (42ㅡ). Også her erkjennes det at man mangler god kvalitet på evidensen for behandlingseffekt. Likevel oppfatter vi veilederen som betydelig proaktiv i å anbefale klipping av tungebåndet. Symptomene hos mor og barn som listes opp som mulig forårsaket av stramt tungebånd, er så generelle og omfattende at majoriteten av ammende mødre vil kunne føle seg inkludert av disse. Eksempelvis er problemer som smerter ved amming, inkomplett tømming av brystet, at barnet har problemer med å oppnå og holde sugetak eller sovner på brystet før fullført måltid, svært vanlige og som regel forbigående i forbindelse med oppstart av amming.

Vi frykter at veilederen vil kunne medføre ytterligere $ø$ kning i press om klipping av tungebåndet. Vi er lite beroliget over forfatternes utsagn om at «det at det ikke er evidens av god kvalitet som dokumenterer effekt av behandlingen betyr ikke at behandlingen ikke hjelper» (42). Når man står mellom to behandlingsalternativer der det er lite evidens for at den radikale behandlingsmåten er bedre enn den konservative, mener vi det klokeste valget er å velge det alternativet som gir minst skade og smerte for barnet.

\section{Konklusjon}


Flertallet av barn med stramt tungebånd har ikke ammeproblemer, og barn med ammeproblemer har ofte ikke stramt tungebånd. God ammeveiledning må alltid prøves ut før kirurgisk behandling overveies. Selv om det er begrenset evidens for effekt, foreslår flertallet av systematiske oversikter og veiledere at klipping kan forsøkes for å redusere ammeproblemer dersom det samtidig diagnostiseres stramt tungebånd. Det foreligger imidlertid ikke gode studier på langtidseffekt av kirurgisk behandling. Et irreversibelt inngrep som utføres på et individ som ikke er samtykkekompetent, bør kun utføres etter en grundig vurdering av inngrepets nytte versus risiko og smerte for det nyfødte barnet. Neppe noen annen kirurgisk prosedyre i Norge utføres nå hyppigere i nyfødtperioden enn klipping av tungebåndet. Økningen vi har sett de siste årene, maner til ekstra varsomhet for å unngå overdiagnostikk og overbehandling.

Artikkelen inkluderer opplysninger fra Norsk pasientregister. Forfatterne er eneansvarlig for tolkning og presentasjon av de utleverte opplysningene, og registerforvalter for pasientregisteret har ikke ansvar for analyser eller tolkninger basert på disse.

Artikkelen er fagfellevurdert.

\section{LITTERATUR}

1. Jin RR, Sutcliffe A, Vento M et al. What does the world think of ankyloglossia? Acta Paediatr 2018; 107: 1733-8. [PubMed][CrossRef]

2. Lalakea ML, Messner AH. Ankyloglossia: does it matter? Pediatr Clin North Am 2003; 50:381-97. [PubMed][CrossRef]

3. Isaacson GC. Ankyloglossia (tongue-tie) in infants and children. UpToDate. https://www.uptodate.com/contents/ankyloglossia-tongue-tie-in-infants-and-children Lest 27.7.2021.

4. Messner AH, Walsh J, Rosenfeld RM et al. Clinical consensus statement: ankyloglossia in children. Otolaryngol Head Neck Surg 2020; 162: 597-611. [PubMed][CrossRef]

5. O'Shea JE, Foster JP, O'Donnell CP et al. Frenotomy for tongue-tie in newborn infants. Cochrane Database Syst Rev 2017; 3: CDo11065. [PubMed]

6. Lisonek M, Liu S, Dzakpasu S et al. Changes in the incidence and surgical treatment of ankyloglossia in Canada. Paediatr Child Health 2017; 22:382-6. [PubMed][CrossRef]

7. Walsh J, Links A, Boss E et al. Ankyloglossia and lingual frenotomy: national trends in inpatient diagnosis and management in the United States 1997-2012. Otolaryngol Head Neck Surg 2017; 156: 73540. [PubMed][CrossRef]

8. Walsh J, Tunkel D. Diagnosis and treatment of ankyloglossia in newborns and infants - A review. JAMA Otolaryngol Head Neck Surg 2017; 143: 1032-9. [PubMed][CrossRef]

9. Ballard JL, Auer CE, Khoury JC. Ankyloglossia: assessment, incidence, and effect of frenuloplasty on the breastfeeding dyad. Pediatrics 2002; 110: e63. [PubMed][CrossRef]

10. Segal LM, Stephenson R, Dawes M et al. Prevalence, diagnosis, and treatment of ankyloglossia: methodologic review. Can Fam Physician 2007; 53: 1027-33. [PubMed]

11. Messner AH, Lalakea ML. Ankyloglossia: controversies in management. Int J Pediatr Otorhinolaryngol 2000; 54: 123-31. [PubMed][CrossRef]

12. Power RF, Murphy JF. Tongue-tie and frenotomy in infants with breastfeeding difficulties: achieving a balance. Arch Dis Child 2015; 100: 489-94. [PubMed][CrossRef]

13. Dahl H, Rinvik E. Fordøyelsesorganene. I: Menneskets funksjonelle anatomi. 3. utg. Oslo: Cappelen Damm, 2010: 601-2.

14. Mills N, Pransky SM, Geddes DT et al. What is a tongue tie? Defining the anatomy of the in-situ lingual frenulum. Clin Anat 2019; 32: 749-61. [PubMed][CrossRef]

15. Ferrés-Amat E, Pastor-Vera T, Rodríguez-Alessi P et al. Management of ankyloglossia and breastfeeding difficulties in the newborn: Breastfeeding sessions, myofunctional therapy, and frenotomy. Case Rep Pediatr 2016; 2016:3010594. [PubMed][CrossRef] 
16. Direktoratet for e-helse. ICD-10. Den internasjonale statistiske klassifikasjonen av sykdommer og beslektede helseproblemer. https://finnkode.ehelse.no/\#icd1o/o/o/o/2620294.1 Lest 25.6.2021.

17. Douglas PS. Rethinking "posterior" tongue-tie. Breastfeed Med 2013; 8: 503-6. [PubMed][CrossRef]

18. Hong P, Lago D, Seargeant J et al. Defining ankyloglossia: a case series of anterior and posterior tongue ties. Int J Pediatr Otorhinolaryngol 2010; 74: 1003-6. [PubMed][CrossRef]

19. Norsk barnelegeforening. Pediatriveileder: Stramt tungebånd hos nyfødte.

https://www.helsebiblioteket.no/pediatriveiledere?menuitemkeylev1=11574\&key=262401 Lest 25.6.2021.

20. Schoenwolf G, Bleyl S, Brauer P et al. Development of the pharyngeal apparatus and face. I: Larsen's Human Embryology. 5. utg. Philadelphia, PA: Elsevier/Churchill Livingstone, 2015: 458-6o.

21. Hooda A, Rathee M, Yadav S et al. Ankyloglossia: A review of Current Status. The Internet Journal of Otothinolaryngology 2009; 12:1-8.

22. Smith WL, Erenberg A, Nowak A et al. Physiology of sucking in the normal term infant using realtime US. Radiology 1985; 156:379-81. [PubMed][CrossRef]

23. Monaci G, Woolridge M. Ultrasound video analysis for understanding infant breastfeeding. International Congress of Image Processing (ICIP) Brussels: IEEE, 2011.

https://ieeexplore.ieee.org/document/6115802 Lest 27.7.2021.

24. Elad D, Kozlovsky P, Blum O et al. Biomechanics of milk extraction during breast-feeding. Proc Natl Acad Sci U S A 2014; 111: 5230-5. [PubMed][CrossRef]

25. Geddes DT, Langton DB, Gollow I et al. Frenulotomy for breastfeeding infants with ankyloglossia: effect on milk removal and sucking mechanism as imaged by ultrasound. Pediatrics 2008; 122: e18894. [PubMed][CrossRef]

26. Hogan M, Westcott C, Griffiths M. Randomized, controlled trial of division of tongue-tie in infants with feeding problems. J Paediatr Child Health 2005; 41: 246-50. [PubMed][CrossRef]

27. Kent JC, Ashton E, Hardwick CM et al. Nipple pain in breastfeeding mothers: incidence, causes and treatments. Int J Environ Res Public Health 2015; 12: 12247-63. [PubMed][CrossRef]

28. Ammehjelpen. Stramt eller kort tungebånd. https://ammehjelpen.no/tungeband/ Lest 25.6.2021.

29. Ferrés-Amat E, Pastor-Vera T, Rodriguez-Alessi P et al. The prevalence of ankyloglossia in 302 newborns with breastfeeding problems and sucking difficulties in Barcelona: a descriptive study. Eur J Paediatr Dent 2017; 18: 319-25. [PubMed]

30. Campanha SMA, Martinelli RLC, Palhares DB. Association between ankyloglossia and breastfeeding. CoDAS 2019; 31: e20170264. [PubMed][CrossRef]

31. Sawyer DR, Taiwo EO, Mosadomi A. Oral anomalies in Nigerian children. Community Dent Oral Epidemiol 1984; 12: 269-73. [PubMed][CrossRef]

32. Koay CL, Lim JA, Siar CH. The prevalence of tongue lesions in Malaysian dental outpatients from the Klang Valley area. Oral Dis 2011; 17: 210-6. [PubMed][CrossRef]

33. Sedano HO, Carreon Freyre I, Garza de la Garza ML et al. Clinical orodental abnormalities in Mexican children. Oral Surg Oral Med Oral Pathol 1989; 68:300-11. [PubMed][CrossRef]

34. Webb AN, Hao W, Hong P. The effect of tongue-tie division on breastfeeding and speech articulation: a systematic review. Int J Pediatr Otorhinolaryngol 2013; 77: 635-46. [PubMed][CrossRef]

35. Chinnadurai S, Francis DO, Epstein RA et al. Treatment of ankyloglossia for reasons other than breastfeeding: a systematic review. Pediatrics 2015; 135: e1467-74. [PubMed][CrossRef]

36. Dixon B, Gray J, Elliot N et al. A multifaceted programme to reduce the rate of tongue-tie release surgery in newborn infants: Observational study. Int J Pediatr Otorhinolaryngol 2018; 113: 156-63. [PubMed][CrossRef]

37. Caloway C, Hersh CJ, Baars R et al. Association of feeding evaluation with frenotomy rates in infants with breastfeeding difficulties. JAMA Otolaryngol Head Neck Surg 2019; 145: 817-22. [PubMed] [CrossRef]

38. Francis DO, Krishnaswami S, McPheeters M. Treatment of ankyloglossia and breastfeeding outcomes: a systematic review. Pediatrics 2015; 135: e1458-66. [PubMed][CrossRef]

39. Canadian Agency for Drugs and Technologies in Health. Frenectomy for the correction of Ankyloglossia: A Review of clinical Effectiveness and Guidelines. Ottawa, ON: CADTH Rapid Response Report, 2016.

40. Sundhetdsstyrelsen. Undersøgelse og behandling af ankyloglossi hos ammede spædbørn.

Nasjonal klinisk retningslinje. https://www.sst.dk/da/Opgaver/Patientforloeb-og-kvalitet/Nationalekliniske-retningslinjer-NKR/Puljefinansierede-NKR/Undersoegelse-og-behandling-af-ankyloglossihos-ammede-spaedboern Lest 25.6.2021. 
41. Eriksson M, Johansson S, Nilsson S et al. «Socialstyrelsen behøver utreda tungebandsklipp». Dagens Medicin 16.6.2021. https://www.dagensmedicin.se/opinion/debatt/socialstyrelsen-behoverutreda-tungbandsklipp/?

fbclid=IwAR3XXT3ZlAhnzRdj5Fj7E15oRQdcKPITCfN34sTP2_cktWMXZIiPQcbXFMY Lest 25.6.2021.

42. Nasjonal kompetansetjeneste for amming. Stramt tungebånd - Veileder for diagnostikk og behandling av stramt tungebånd hos spedbarn. Oslo: Oslo universitetssykehus, 2021. https:|/oslouniversitetssykehus.no/seksjon/Nasjonal-kompetansetjeneste-for-

amming/Documents/Veileder\%2oStramt\%2otungebånd.pdf Lest 25.6.2021.

Publisert: 12. august 2021. Tidsskr Nor Legeforen. DOI:10.4045/tidsskr.21.0515

Mottatt 25.6.2021, første revisjon innsendt 7.7.2021, godkjent 27.7.2021.

(C) Tidsskrift for Den norske legeforening 2023. Lastet ned fra tidsskriftet.no 26. april 2023. 